\title{
The efficacy of transcranial magnetic stimulation on migraine: a meta-analysis of randomized controlled trails
}

\author{
Lihuan $\operatorname{Lan}^{1 \dagger}$, Xiaoni Zhang ${ }^{2 \dagger}$, Xiangpen $\mathrm{Li}^{2 \dagger}$, Xiaoming Rong ${ }^{2}$ and Ying Peng ${ }^{2 *}$
}

\begin{abstract}
Objectives: As a non-invasive therapy, whether transcranial magnetic stimulation (TMS) is effective on migraine. This article was aimed to assess the efficacy of TMS on migraine based on randomized controlled trails (RCTs).

Methods: We searched PubMed, Embase and Cochrane Library electronic databases for published studies which compared TMS group with sham group, conducted a meta-analysis of all RCTs.
\end{abstract}

Results: Five studies, consisting of 313 migraine patients, were identified. Single-pulse transcranial magnetic stimulation is effective for the acute treatment of migraine with aura after the first attack $(p=0.02)$. And, the efficacy of TMS on chronic migraine was not significant (OR 2.93; 95\% Cl 0.71-12.15; $p=0.14$ ).

Conclusions: TMS is effective for migraine based on the studies included in the article.

Keywords: Migraine, Transcranial magnetic stimulation, Randomized control trail

\section{Background}

Recently, the incidence of migraine is gradually rising and becoming one of the most common nervous system diseases in the world [1]. According to ICHD-3 (beta version), migraine is divided into migraine without aura, migraine with aura, chronic migraine, complications of migraine, probable migraine and episodic syndromes that may be associated with migraine. Particularly, chronic migraine cause serious damage in the quality of life. However, the effect of the drug therapies, include acute therapies (non-steroidal anti-inflammatory drugs, ergotamine preparations and triptans) and preventive therapies ( $\beta$-blockers, anticonvulsants, tricyclic antidepressants and calcium channel modulators), are not significantly improved the clinical symptoms.

Transcranial magnetic stimulation (TMS), which is a magnetic field created by an electrical current through a coil wrapped around the scalp or skull. The types of TMS include single-pulse TMS, pair-pulses TMS and

\footnotetext{
*Correspondence: docpengy123@163.com

${ }^{\dagger}$ Equal contributors

${ }^{2}$ Department of Neurology, Sun Yat-Sen Memorial Hospital, Sun Yat-Sen University, Number 33, Yingfeng Road, Haizhu District, Guangzhou 510288, China

Full list of author information is available at the end of the article
}

repetitive TMS. In neurophysiology, TMS can measure neural conduction, facilitate or inhibit the electrical activity of cerebral cortex [2]. TMS is a noninvasive technology and the first transcranial magnetic stimulator was introduced to the world in 1984-1985 [3]. Nevertheless, using TMS for a therapy was firstly reported on drug-resistant depressed patients in 1996 [4]. After 30 years later, TMS now can be applied for a diagnostic therapy in many diseases including multiple sclerosis, movement disorder, stroke, epilepsy and so on $[5,6]$. Meanwhile, TMS also can be used for a therapy. There has been reported a series of diseases covering psychiatric disorders (depression, acute mania, schizophrenia, bipolar disease, panic disorder, post-traumatic stress disorder, substance abuse) and neurologic disorders (Parkinson's disease, dystonia, tinnitus, epilepsy, stroke) improved by TMS [7-26]. Furthermore, single-pulse and paired-pulse/double-coil TMS are safety for normal human subjects and patients who suffer from migraine $[2,27]$. However, there is less randomized control trails (RCTs) to identify the efficacy of TMS in migraine at present. Recently, there are some papers reviewed the effect of TMS for migraine [28, 29], but lack a meta-analysis. 
Although there is a meta-analysis about noninvasive brain stimulation in migraine, it reached a conclusion that TMS did not reveal significant effects for any outcome [30], moreover, some new RCTs have revealed that TMS is efficacy for migraine recently.

For the exact mechanism of migraine does not exist so far. It may relate to neural and vascular causes, involving cerebral cell hyper excitability, sensitization of the trigeminovascular pathway, correlative predisposing genes and environmental factors. As for migraine with aura, cortical spreading depression (CSD) proved to be its pathogenesis [31-33]. CSD, an inhibition zone of cortical activity after stimulating vertebrate's cerebral cortex, and the zone would move to adjacent cortex at a speed of $2-5 \mathrm{~mm} / \mathrm{min}$. CSD may change the cerebral blood flow and result in headache. Currently, there are evidence that single pulse-TMS can suppress CSD in animal experiment [34]. Correspondingly, some clinical trials are developed to verify whether TMS is effective for migraine. This article provides an update on the effect of TMS in migraine from randomized control trails.

\section{Methods}

According to the Preferred Reporting Items for Systematic Reviews [35], a protocol of study-search strategies, outcome measurements, and methods of statistical analysis was prepared in advance.

\section{Study-search strategy}

In April 2017, the PubMed, Embase and the Cochrane Library electronic databases were researched in the following medical subject headings (MeSH): [Title/Abstract] "Migraine Disorders", "Migraine", "Migrain", "Transcranial Magnetic Stimulation" and "Randomized", "Randomized Study". Moreover, the related articles function was also used to broaden the search, and all studies, abstracts were reviewed without restriction to regions, publication types, or languages.

\section{Selection criteria}

1. The study was a randomized controlled trail that compared transcranial magnetic stimulation with sham group; 2. The study had the quantitative outcomes.

\section{Data extraction}

The data was extracted by two independent authors (Lihuan, L and Xiaoni, Z) as following: (1) Study design.

(2) Number of patients in active group and sham group.

(3) Device and treatment parameters. (4) The change of headache frequency.

Furthermore, all controversies were settled by consensus. In regard to incomplete data, we contacted the author for detail information. While, there is one study missing the original data (Chiara Rapinesi et al.) [36].

\section{Quantitative and statistical analysis}

For the level of evidence, the Cochrane risk of bias tool was used to evaluate the quality of RCTs [37]. And the odds ratio (OR) was used to assess dichotomous variables, with results being reported using 95\% confidence intervals (CI). Heterogeneity within study results was evaluated using Chi squared test and $I^{2}$ statistic. Higher $\mathrm{X}^{2}$ and $\mathrm{I}^{2}$ statistic manifests more heterogeneity among studies. If $p$ value was more than 0.1 and $\mathrm{I}^{2}$ was less than $50 \%$, a random-effect model was used. If not, a fixedeffect model was used [37].

Risk of bias summary was used to evaluate if there were potential publication bias. All statistical analyses were done by Review Manager 5.0 (Cochrane Collaboration).

\section{Results}

The characteristics of included studies are described in Table 1 . Sixty three studies were screened using predefined search strategy (Fig. 1). Eight were excluded as duplication. Forty nine were excluded because of nonrandomized study. And 1 was excluded for lacking of exact data. Five studies, consisting of 313 migraine patients, contributed to this meta-analysis [38-42]. And the earliest was reported in 2004, the latest study was published in 2016.

\section{Sensitivity analysis and publication bias}

All studies are RCTs, the result of heterogeneity among studies are showed in Fig. 2. Four studies were related to chronic migraine, one study researched TMS for acute treatment of migraine with aura. For all studies, the heterogeneity is as following: $X^{2}=7.96, P=0.09, \mathrm{I}^{2}=$ $50 \%$. While, when we combined 4 chronic migraine studies, excepted migraine with aura, the heterogeneity change to: $X^{2}=6.49, P=0.09, \mathrm{I}^{2}=54 \%$. Given the small sample sizes in this study, the change of heterogeneity is slight significance. Figure 3 shows risk of bias summary of researches included in this meta-analysis.

\section{Effect on migraine with aura (Fig. 4a)}

There was one RCT (Richard B Lipton et al.) assessed the efficacy of TMS on migraine with aura. According to the study, more patients were pain-free at $2 \mathrm{~h}$ posttreatment and there is significant that single-pulse transcranial magnetic stimulation is effective for the acute treatment of migraine with aura after the first attack $(p=0.02)$.

\section{Effect on chronic migraine (Fig. 4b)}

There were 4 RCTs researched the effect of TMS on chronic migraine. And statistical heterogeneity was detected among the trails $\left(\mathrm{X}^{2}=6.49, p=0.09, \mathrm{I}^{2}=54 \%\right)$. Moreover, the efficacy of TMS on chronic migraine was not significant (OR 2.93; 95\% CI $0.71-12.15 ; p=0.14$ ). 


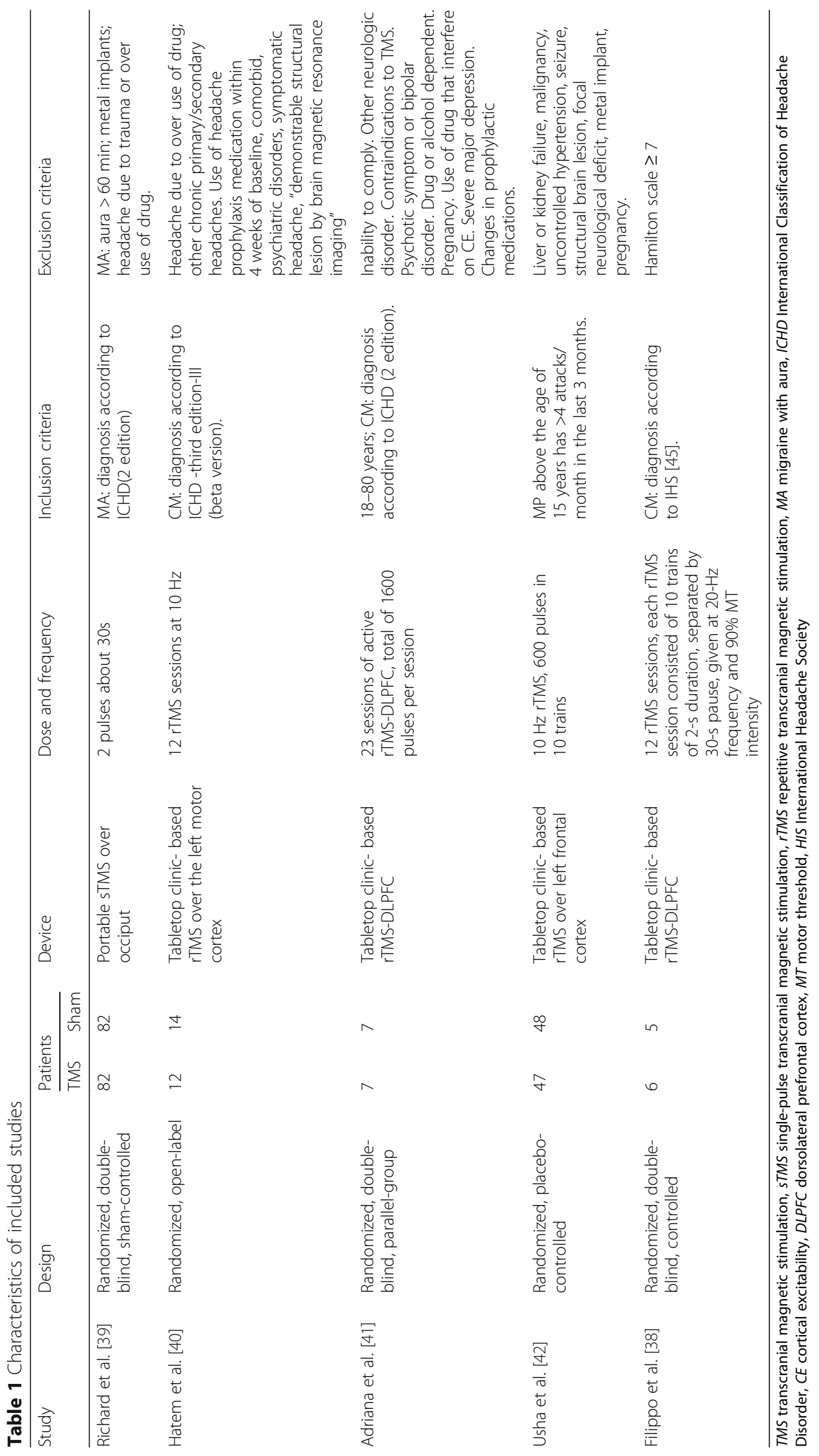




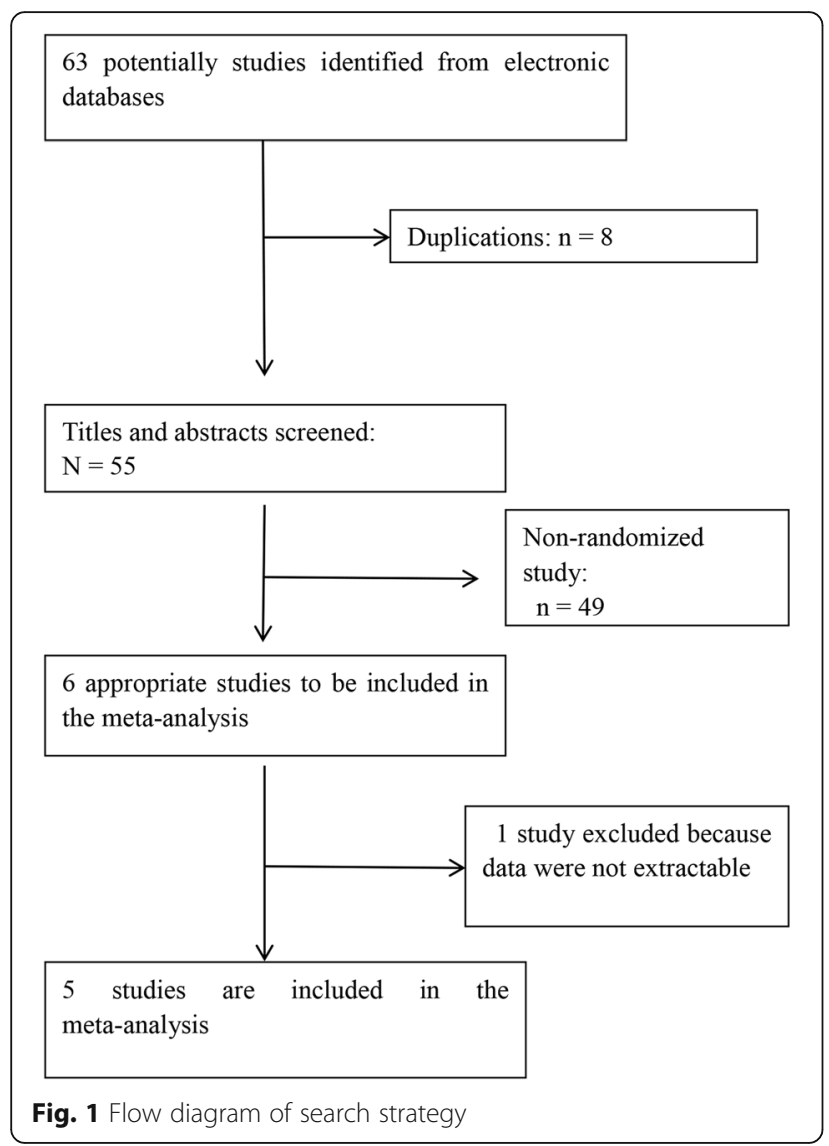

\section{Effect on migraine (Fig. 2)}

For all studies, significant statistical heterogeneity was detected $\left(\chi^{2}=7.96, p=0.09, \mathrm{I}^{2}=50 \%\right)$. And statistically significant effect of group (TMS group, control group) was found by analyzing all trials (OR 2.87; 95\% CI $1.17-7.03 ; p=0.02$ ).

\section{Discussion}

Migraine is a kind of chronic headache relating to cortical excitability. As a noninvasive therapy, TMS can activate (or suppress) the cortex excitability. In 2013, a Statement from the European Headache Federation

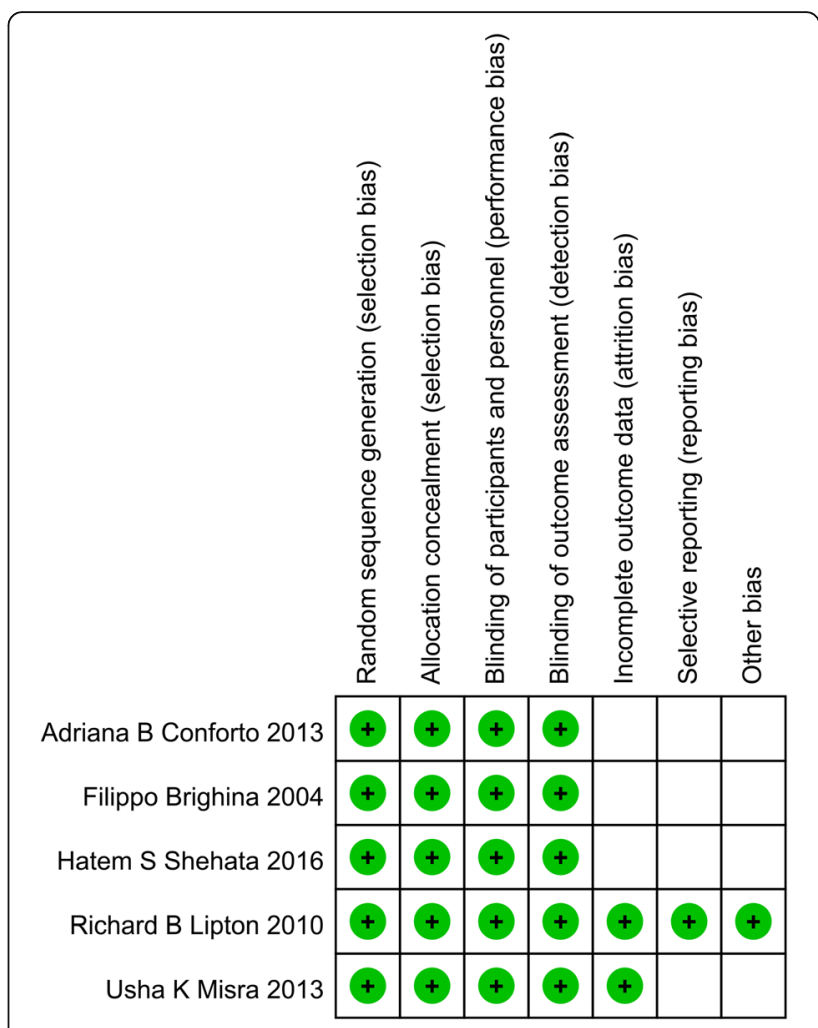

Fig. 3 Risk of bias summary of researches included in this meta-analysis

indicates that using of a noninvasive therapy in chronic headaches is not evidence based at present and a neurostimulator should be considered only all alternative drug and behavioural therapies as recommended by international guidelines have failed and medication overuse headache is excluded, due to the lack of proper RCTs [43]. Because there are limited drugs that can improve the quality of life for people with the migraine, and TMS as a promising therapy which can facilitate or inhibit the electrical activity of cerebral cortex and there are some existing RCTs reveal that TMS can relieved headache. Nonetheless, there are few meta-analyses about the effect of TMS for migraine. By combining RCTs and meta-analysis, we hope to evaluate whether TMS can

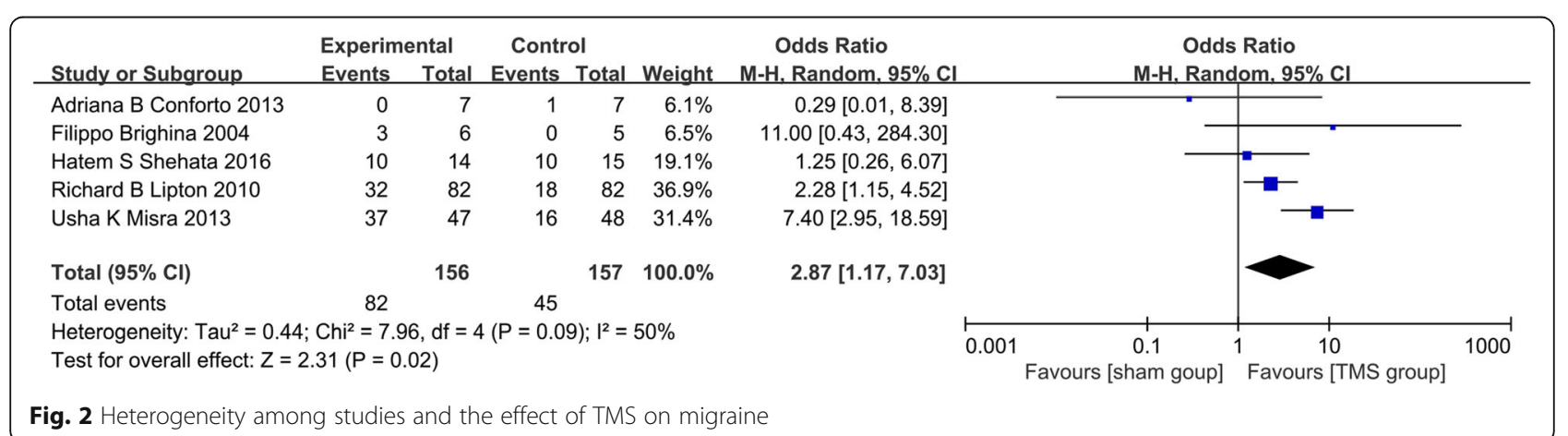




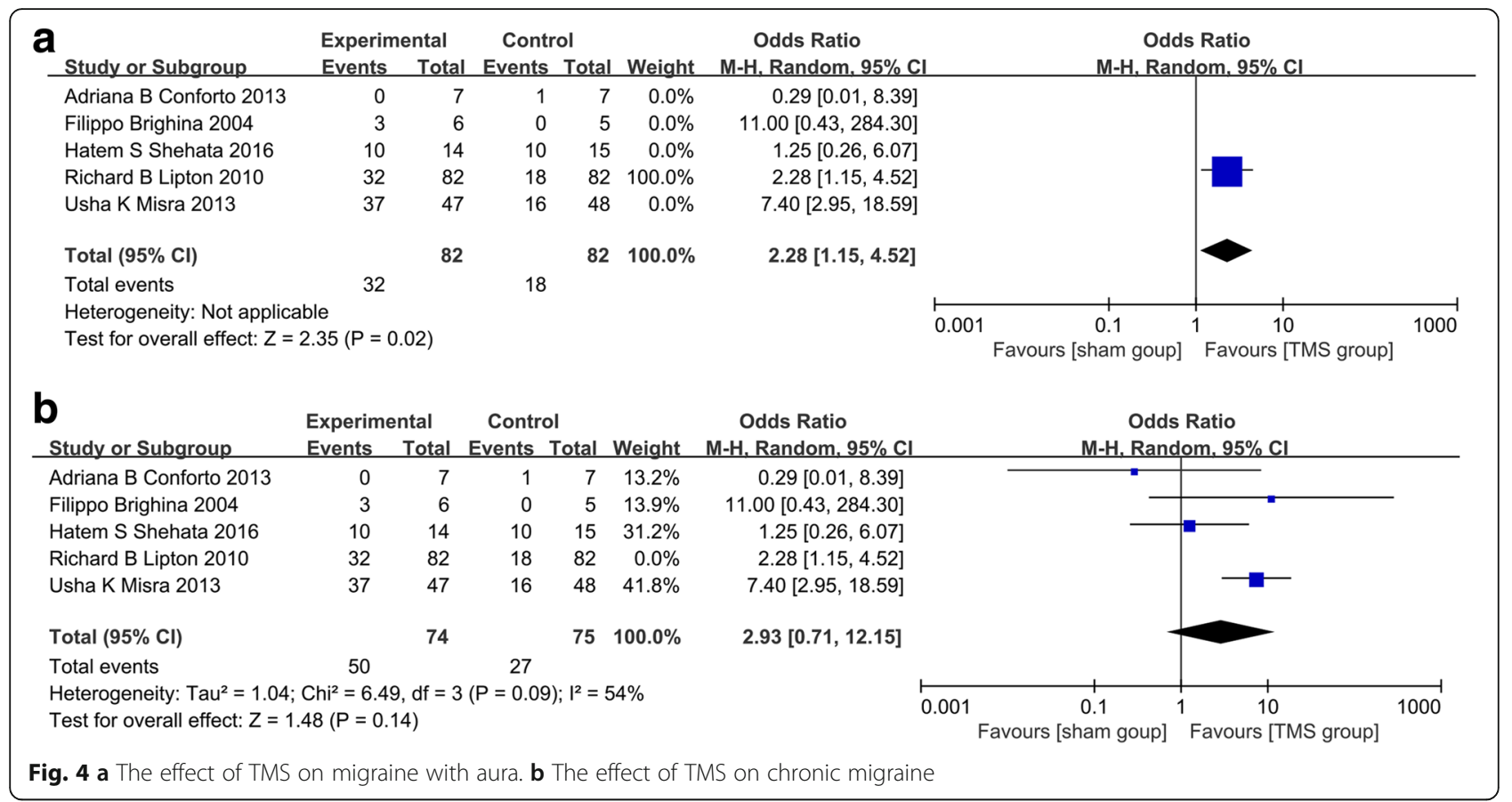

relieve headache and to expand its clinical application. So we decide to assess the effect of TMS on migraine by synthesizing evidences.

In this meta-analysis, 5 RCTs including 313 patients comparing the efficacy of TMS group with control group indicated that TMS was significantly effective for migraine. However, the doses and frequency of TMS in these RCTs were different. And which doses could help to improve the headache frequency of migraine doesn't reach common understanding. In an open labeled study, Usha et al. reported that high frequency repetitive transcranial magnetic stimulation (rTMS) was effective and well tolerated for migraine prophylaxis [42]. Besides, in other study, M Teepker et al. reported that no statistically significant difference between low-frequency rTMS with sham stimulation was found [44]. In the present meta-analysis, 5 RCTs used a higher frequency $(\geq 10 \mathrm{~Hz})$ stimulation. So we considered that higher frequency stimulation may reach an obvious effect. However, the reasons for variability are not only the dose but also the side, location of stimulation, type of coil and the number of sessions. The $5 \mathrm{RCTs}$ were generally delivered at different frequency with a figure-eight coil positioned over the left motor cortex. Due to the difference in the side, location of stimulation, type of coil and the number of sessions, the efficacy of magnetic signal on electrical activity of cerebral cortex is different. Nevertheless, there is not a common standard of TMS on migraine at present. Given that, future well-designed RCTs are needed to confirm which dose, side, and location of stimulation, type of coil or the number of sessions is more effective for migraine.
Transcranial magnetic stimulation, a novel treatment method, is considered to be effective for migraine in this meta-analysis. However, there is an inevitable problem that these RCTs did not have a standard control group. In four RCTs, there were active TMS group and sham TMS group [38, 39, 41, 42]. In one RCT, there were active TMS group and botulinum toxin-A injection group [40]. Therefore, we have no idea that whether TMS is superior to conventional therapy. It is necessary to conduct more clinical trials to assess the efficacy of TMS on migraine in the future.

When evaluated the effect of TMS on chronic migraine, we reached a conclusion that there was not statistically significant difference in effect between active TMS group and sham TMS group. In light of this, we put forward two hypotheses: firstly, chronic migraine is a chronic pathogenic process and the threshold of pain had been raised. Although TMS can change the excitability of cortex, it needs more time to do this. Secondly, due to the small sample, this conclusion was not definite. Future well-designed RCTs are needed to confirm this conclusion.

Besides, this meta-analysis has some limitations as following: first, the main limitation is that we only included published data and there were 5 RCTs included in this article. The published bias comes to an unavoidable issue. Therefore, the conclusion came from synthesizing evidence should be considered with caution. And in order to improve the reliability of this meta-analysis, we only take RCT into account. Although a meta-analysis of RCTs can provide a more reliable result, due to the lack 
of studies, only 5 RCTs included in this meta-analysis prevented us from reaching a more authentic outcome. Second, for all studies included in the analysis, patients were not a grouped by severity of pathogenic condition, sexuality or age and so on. So the efficacy of TMS should be taken into consideration. Third, the patients included in this paper mostly came from general hospitals or major institutions, so the patients might not represent patient populations in the world. Fourth, due to the difference of original data on studies included in the analysis, this meta-analysis did not make full use of data in studies.

\section{Conclusion}

In summary, this meta-analysis indicates that TMS is effective for migraine based on the studies included in the article. For the stimulation parameters, using figure-of8-shaped coil over the left motor cortex with higher frequency may be effect based on the studies included in the article. However, because of above limitations, the efficacy of TMS on migraine should be tasted on more RCTs in the future.

\section{Abbreviations}

Cl: Confidence intervals; CSD: Cortical spreading depression; MeSH: Medical subject headings; OR: Odds ratio; RCTs: Randomized controlled trails; rTMS: repetitive transcranial magnetic stimulation; TMS: Transcranial magnetic stimulation

\section{Acknowledgements}

Not applicable.

\section{Funding}

The study was supported by National Natural Science Foundation of China (No. 81572481) to Ying Peng, International Collaboration Program of Universities in Guangdong Province (No.2012hjhz001) and the Key Project of Product, Study and Research of Guangzhou city (No. 1561000181) to Ying Peng, National Natural Science Foundation of China (No. 81502167) to Xiaoming Rong.

\section{Availability of data and materials}

The datasets used and/or analyzed during the current study are available from the corresponding author on reasonable request.

\section{Authors' contributions}

YP had full access to the data in this study and takes responsibility for the data and the accuracy of the data analysis. Study concept and design: YP, LL. Acquisition of data: XZ, LL. Analysis and interpretation of data: LL, XZ. Drafting of the manuscript: LL, XL. Statistical analysis: LL, XR. All authors read and approved the final manuscript.

\section{Ethics approval and consent to participate}

Not applicable.

\section{Consent for publication}

Not applicable.

\section{Competing interests}

The authors declare that they have no competing interests.

\section{Publisher's Note}

Springer Nature remains neutral with regard to jurisdictional claims in published maps and institutional affiliations.

\section{Author details}

${ }^{1}$ Sun Yat-Sen University, Guangzhou 510288, China. ${ }^{2}$ Department of Neurology, Sun Yat-Sen Memorial Hospital, Sun Yat-Sen University, Number 33, Yingfeng Road, Haizhu District, Guangzhou 510288, China.

Received: 1 June 2017 Accepted: 2 August 2017

Published online: 22 August 2017

\section{References}

1. Collaborators GBoDS (2015) Global, regional, and national incidence, prevalence, and years lived with disability for 301 acute and chronic diseases and injuries in 188 countries, 1990-2013:a systematic analysis for the global burden of disease study 2013. Lancet (Lond, Engl) 386:743-800

2. Sulekha Ananda JH (2002) TMS Neurophysiological applications and safety. Brain Cogn 50:366-386

3. Horvath JC, Perez JM, Forrow L, Fregni F, Pascual-Leone A (2011) Transcranial magnetic stimulation: a historical evaluation and future prognosis of therapeutically relevant ethical concerns. J Med Ethics 37(3): 137-143. doi:10.1136/jme.2010.039966

4. Pascual-Leone A, Rubio B, Pallardó F, Catalá MD (1996) Rapid-rate transcranial magnetic stimulation of left dorsolateral prefrontal cortex in drug-resistant depression. Lancet 348(9022):233-237. doi:10.1016/s0140-6736(96)01219-6

5. Di Lazzaro V, Oliviero A, Profice P, Ferrara L, Saturno E, Pilato F, Tonali P (1999) The diagnostic value of motor evoked potentials. Clin Neurophysiol 110(7):1297-1307. doi:10.1016/S1388-2457(99)00060-7

6. Curra A, Modugno N, Inghilleri M, Manfredi M, Hallett M, Berardelli A (2002) Transcranial magnetic stimulation techniques in clinical investigation. Neurology 59(12):1851-1859. doi:10.1212/01.wnl.0000038744.30298.d4

7. Takeuchi N, Tada T, Toshima M, Matsuo Y, Ikoma K (2009) Repetitive transcranial magnetic stimulation over bilateral hemispheres enhances motor function and training effect of paretic hand in patients after stroke. J Rehabil Med Off J Uems Eur Board Phys Rehabil Med 41(13):1049-1054

8. Santiago-Rodríguez E, Cárdenas-Morales L, Harmony T, Fernández-Bouzas A, Porras-Kattz E, Hernández A (2008) Repetitive transcranial magnetic stimulation decreases the number of seizures in patients with focal neocortical epilepsy. Seizure 17(8):677-683

9. Santiago RE, Cardenas ML, Harmony T (2006) P06.15 analysis of cortical excitability during repetitive trancranial magnetic stimulation in partial epilepsy. Clin Neurophysiol 117(Suppl 1):157-158

10. Prasko J, Záleský R, Bares M, Horácek J, Kopecek M, Novák T, Pasková B (2007) The effect of repetitive transcranial magnetic stimulation (rTMS) add on serotonin reuptake inhibitors in patients with panic disorder: a randomized, double blind sham controlled study. Neuro Endocrinol Lett 28(1):33-38

11. Praharaj SK, Ram D, Arora M (2009) Efficacy of high frequency (rapid) suprathreshold repetitive transcranial magnetic stimulation of right prefrontal cortex in bipolar mania: a randomized sham controlled study. J Affect Disord 117:3-146

12. Pascual-Leone A, Rubio B, Pallardó F, Catalá MD (1996) Rapid-rate transcranial magnetic stimulation of left dorsolateral prefrontal cortex in drug-resistant depression. Lancet 348:9022-9233

13. Nahas Z, Kozel FA, Li X, Anderson B, George MS (2003) Left prefrontal transcranial magnetic stimulation (TMS) treatment of depression in bipolar affective disorder: a pilot study of acute safety and efficacy. Bipolar Disord 5(5):40-47

14. Matheson SL, Green MJ, Loo C, Carr VJ (2010) Quality assessment and comparison of evidence for electroconvulsive therapy and repetitive transcranial magnetic stimulation for schizophrenia: a systematic metareview. Schizophr Res 118(1-3):201-210

15. Lefaucheur JP, Drouot X, Von RF, Ménard-Lefaucheur I, Cesaro P, Nguyen JP (2005) Improvement of motor performance and modulation of cortical excitability by repetitive transcranial magnetic stimulation of the motor cortex in Parkinson's disease. Clin Neurophysiol 115(115):2530-2541

16. Kaptsan A, Yaroslavsky Y, Applebaum J, Belmaker RH, Grisaru N (2003) Right prefrontal TMS versus sham treatment of mania: a controlled study. Bipolar Disord 5(5):36-39

17. Hoffman RE, Gueorguieva R, Hawkins KA, Varanko M, Boutros NN, Wu YT, Carroll K, Krystal JH (2005) Temporoparietal transcranial magnetic stimulation for auditory hallucinations: safety, efficacy and moderators in a fifty patient sample. Biol Psychiatry 58:2-97 
18. Fregni F, Pascualleone A (2007) Technology insight: noninvasive brain stimulation in neurology-perspectives on the therapeutic potential of rTMS and tDCS. Nat Clin Pract Neurol 3(7):383-393

19. De RD, De MG, Menovsky T, Sunaert S, Kovacs S (2007) Electrical stimulation of auditory and somatosensory cortices for treatment of tinnitus and pain. Prog Brain Res 166:1-377

20. Couturier $\mathrm{U}$ (2005) Efficacy of rapid-rate repetitive transcranial magnetic stimulation in the treatment of depression: a systematic review and metaanalysis. J Psychiatry Neurosci JPN 30(2):83-90

21. Cohen H, Kaplan Z, Kotler M, Kouperman I, Moisa R, Grisaru N (2004) Repetitive transcranial magnetic stimulation of the right dorsolateral prefrontal cortex in posttraumatic stress disorder: a double-blind, placebocontrolled study. Am J Psychiatr 161(3):515-524

22. Camprodon JA, Martínez-Raga J, Alonso-Alonso M, Shih MC, Pascual-Leone A (2007) One session of high frequency repetitive transcranial magnetic stimulation (rTMS) to the right prefrontal cortex transiently reduces cocaine craving. Drug Alcohol Depend 86(1):91-94

23. Borich M, Arora S, Kimberley TJ (2009) Lasting effects of repeated rTMS application in focal hand dystonia. Restor Neurol Neurosci 27:1-55

24. Behzad Elahi MD, Behrad Elahi MD, FRCPC RCMM (2009) Effect of transcranial magnetic stimulation on Parkinson motor function-systematic review of controlled clinical trials. Mov Disord 24(3):357-363

25. Avery $\mathrm{DH}$, Holtzheimer PE III, Fawaz W et al A controlled study of repetitive Transcranial magnetic stimulation in medication-resistant major depression. Biol Psychiatry 59(2):187-194. doi:10.1016/j.biopsych.2005.07.003

26. Gershon AA, Dannon PN, Grunhaus L (2003) Transcranial magnetic stimulation in the treatment of depression. Am J Psychiatry 160(5):835-845. doi:10.1176/appi.ajp.160.5.835

27. Dodick DW, Schembri CT, Helmuth M, Aurora SK (2010) Transcranial magnetic stimulation for migraine: a safety review. Headache 50(7):1153-1163. doi:10. 1111/j.1526-4610.2010.01697.x

28. Zhu S, Marmura MJ (2016) Non-invasive Neuromodulation for headache disorders. Curr Neurol Neurosci Rep 16:2-11. doi:10.1007/s11910-015-0620-7

29. Schwedt TJ, Vargas B (2015) Neurostimulation for treatment of migraine and cluster headache. Pain Med 16(9):1827-1834. doi:10.1111/pme.12792

30. Shirahige L, Melo L, Nogueira F, Rocha S, Monte-Silva K (2016) Efficacy of noninvasive brain stimulation on pain control in migraine patients: a systematic review and meta-analysis. Headache 56(10):1565-1596. doi:10.1111/head.12981

31. AAP L (1944) Spreading depression of activity in cerebral cortex. J Neurophysiol 7:359-390

32. Cutrer FM, Sorensen AG, Weisskoff RM, Ostergaard L, Sanchez del Rio M, Lee EJ, Rosen BR, Moskowitz MA (1998) Perfusion-weighted imaging defects during spontaneous migrainous aura. Ann Neurol 43(1):25-31. doi:10.1002/ana.410430108

33. Hadjikhani N, Sanchez Del Rio M, Wu O et al (2001) Mechanisms of migraine aura revealed by functional MRI in human visual cortex. Proc Natl Acad Sci U S A 98(8):4687-4692. doi:10.1073/pnas.071582498

34. Holland PR, Schembri CT, Fredrick JP, Goadsby PJ (2009) Transcranial magnetic stimulation for the treatment of migraine Aura. Neurology 72(Suppl 1):A250

35. Liberati A, Altman DG, Tetzlaff J et al (2009) The PRISMA statement for reporting systematic reviews and meta-analyses of studies that evaluate health care interventions: explanation and elaboration. Epidemiol Biostatistics Public Health 6(4):e1-e34

36. Rapinesi C, Del CA, Scatena P et al (2016) Add-on deep Transcranial magnetic stimulation (dTMS) for the treatment of chronic migraine: a preliminary study. Neurosci Lett 623:7-12

37. Higgins JP, Green S (2010) Cochrane handbook for systematic reviews of interventions. Naunyn-Schmiedeberg's Arch Exp Pathol Pharmakol (2011) 14:S38

38. Brighina F, Piazza A, Vitello G, Aloisio A, Palermo A, Daniele O, Fierro B (2004) rTMS of the prefrontal cortex in the treatment of chronic migraine: a pilot study. J Neurol Sci 227(1):67-71. doi:10.1016/j.jns.2004.08.008

39. Lipton RB, Dodick DW, Silberstein SD, Saper JR, Aurora SK, Pearlman SH, Fischell RE, Ruppel PL, Goadsby PJ (2010) Single-pulse transcranial magnetic stimulation for acute treatment of migraine with aura: a randomised, doubleblind, parallel-group, sham-controlled trial. Lancet Neurol 9(4):373-380. doi:10.1016/s1474-4422(10)70054-5

40. Shehata HS, Esmail EH, Abdelalim A, El-Jaafary S, Elmazny A, Sabbah A Shalaby NM (2016) Repetitive transcranial magnetic stimulation versus botulinum toxin injection in chronic migraine prophylaxis: a pilot randomized trial. J Pain Res 9:771-777. doi:10.2147/JPR.S116671
41. Conforto AB, Amaro E, Gonçalves AL, Mercante JPP, Guendler VZ, Ferreira JR, Kirschner CCFB, Peres MFP (2014) Randomized, proof-of-principle clinical trial of active transcranial magnetic stimulation in chronic migraine. Cephalalgia 34(6):464-472. doi:10.1177/0333102413515340

42. Misra UK, Kalita J, Bhoi SK (2013) High-rate repetitive transcranial magnetic stimulation in migraine prophylaxis: a randomized, placebo-controlled study. J Neurol 260(11):2793-2801. doi:10.1007/s00415-013-7072-2

43. Martelletti $P$, Jensen $R H$, Antal $A$, Arcioni R, Brighina F, de Tommaso M, Franzini A, Fontaine D, Heiland M, Jürgens TP, Leone M, Magis D, Paemeleire K, Palmisani S, Paulus W, May A (2013) Neuromodulation of chronic headaches position: position statement from the European headache federation. J Headache Pain 14:86

44. Teepker M, Hotzel J, Timmesfeld N, Reis J, Mylius V, Haag A, Oertel WH, Rosenow F, Schepelmann K (2010) Low-frequency rTMS of the vertex in the prophylactic treatment of migraine. Cephalalgia 30(2):137-144. doi:10.1111/j. 1468-2982.2009.01911.x

45. Olesen J, Busser MG, Diener HD, Dodick D, First M, Goadsby PJ, Gobel H, Mja L, Lance JW (2004) Headache classification Subcommittee of the International Headache Society. The international classification of headache disorders: 2nd edition. Cephalalgia 24(Suppl 1):S9-160

\section{Submit your manuscript to a SpringerOpen ${ }^{\circ}$ journal and benefit from:}

- Convenient online submission

- Rigorous peer review

- Open access: articles freely available online

- High visibility within the field

Retaining the copyright to your article

Submit your next manuscript at $>$ springeropen.com 